\title{
Discursos do mundo do trabalho nos livros didáticos do ensino médio*
}

\author{
Rosanne Evangelista Dias \\ Universidade Federal do Rio de Janeiro, Colégio de Aplicação
}

\section{Rozana Gomes de Abreu}

Universidade do Estado do Rio de Janeiro, Programa de Pós-Graduação em Educação

\section{Introdução}

Ao longo de quase uma década, políticas curriculares para o ensino médio têm sido produzidas e difundidas no Brasil. No âmbito federal, documentos constituintes da reforma do ensino médio, como os Parâmetros Curriculares Nacionais (PCNEM) e as Diretrizes Curriculares Nacionais (DCNEM), expressam as principais orientações das propostas formuladas pelo campo oficial e, como outros, auxiliam na divulgação da reforma, formando uma das fases de difusão da política produzida. Cabe aqui ressaltarmos que as políticas curriculares são parte da reforma e, como tal, são formadas por práticas, concepções, valores e intenções de vários sujeitos nos múltiplos espaços a que pertencem no contexto educacional e social.

* Este artigo é derivado da pesquisa "A integração curricular em textos de ciências do ensino médio", aprovada pelo Conselho Nacional de Desenvolvimento Científico e Tecnológico (CNPq) e coordenada por Alice Casimiro Lopes.
Dessa forma, outros textos também devem ser analisados para a melhor compreensão da constituição da política curricular, entre os quais destacamos o livro didático. A produção e a circulação, assim como a instituição de um Programa Nacional do Livro Didático (PNLD) para o ensino médio, podem ser entendidas como outro momento de difusão e de regulação da reforma curricular. Nesse processo, participam outros sujeitos (autores dos livros, equipes de produção de materiais de apoio para o professor, como os manuais do professor) e instituições (editoras) que "reinterpretam os princípios da reforma e traduzem para essa nova linguagem os significados e sentidos da reforma curricular" (Dias, 2004, p. 4.485). Realizam, assim, outro processo de recontextualização (Bernstein, 1996, 1998) dos textos curriculares oficiais, processo no qual discursos são retirados do seu local de origem e colocados em outros locais que possuem outras relações e sujeitos que influenciam a produção de novos significados para os recortes estabelecidos.

Muitos trabalhos têm analisado os discursos dos documentos oficiais da reforma do ensino médio e 
como esses discursos vêm sendo reinterpretados em outros contextos de produção curricular (Abreu \& Gomes, 2004; Dias, 2004; Mello, 2004; Silva \& Lopes, 2004),. Destacamos neste artigo a análise dos discursos sobre o mundo do trabalho, recontextualizados nos textos dos livros didáticos, apresentando sentidos e significados que o conceito configura nesses materiais.

Iniciamos este estudo com uma breve análise de como as reformas curriculares têm focalizado, em seus discursos de mudança, uma relação mais estreita da educação com a economia, no contexto da globalização e da sociedade do conhecimento/da informação. Tal contexto constrói uma base para a incorporação de conceitos empregados no mundo empresarial para o currículo escolar, como é o exemplo do conceito das competências, entre outros. Esses discursos recontextualizados em diversas reformas curriculares no mundo têm como finalidade a performatividade do futuro trabalhador e do estudante nos diversos processos de avaliação aos quais deverão se submeter, valorizando um ensino que "efetivamente propicie um aprendizado útil à vida e ao trabalho" (Brasil, 1999, p. 2).

Na seção seguinte, analisamos os livros didáticos como textos constituintes de políticas curriculares e, dessa forma, também produtores de novos sentidos e significados dos discursos circulantes sobre o mundo do trabalho. Por fim, analisamos, na coleção intitulada "De olho no mundo do trabalho" (livros didáticos e encartes de assessoria pedagógica), da editora Scipione, como esses discursos são recontextualizados pelos diferentes autores das disciplinas química, biologia, matemática e física. Tencionamos analisar tais discursos buscando compreender suas relações com as finalidades da reforma, entendendoos como resultado de processos de recontextualização das políticas curriculares.

\section{Reformas curriculares e a formação para o mundo do trabalho}

Podemos identificar nos variados documentos das reformas curriculares uma análise contextual do mun- do globalizado e em permanente mutação. Esse discurso, que acentua inexoráveis mudanças nos campos científico, social e econômico, credita à educação papel relevante, na condição de portadora de uma nova concepção de ensino que dê conta das atuais circunstâncias em que o mundo vive. Embora reconheçamos as interfaces da globalização com os aspectos cultural, político, econômico, nos deteremos neste último para desenvolver as análises sobre os discursos produzidos no âmbito das reformas curriculares do ensino médio, tendo como foco a formação para o mundo do trabalho. Diante das ações de reestruturação econômica presentes no mundo globalizado, devemos indagar-nos, a exemplo do que fazem Burbules e Torres (2004), como os processos de reestruturação econômica vêm afetando a educação ao redor do mundo.

Os processos de globalização têm produzido alterações significativas especialmente "na organização da produção e em sua relação com o conhecimento e informação" (Morrow \& Torres, 2004, p. 29). Essas mudanças acabam por influenciar o campo da educação, acarretando, no plano do discurso e da prática, novas relações de ensino e aprendizagem. Para Bernstein (1996), essa relação entre conhecimento/ informação e a organização da produção na sociedade contemporânea cria uma idéia de mercado de conhecimento e conhecedores, e dessa nova relação entre conhecimento e sujeito novas relações de mercado se estabelecem, movimentando, substituindo e excluindo pessoas que não estejam adaptadas às mudanças do mundo. Concordamos com Lopes (2004b, p. 117) que a educação não deve estar submetida aos critérios econômicos e ao mercado, pois desse modo "a educação e o conhecimento importam apenas quando podem gerar vantagens econômicas".

Uma das maiores crises provocadas pela reestruturação econômica ocorre no campo do trabalho. A despeito de o discurso do contexto científicotecnológico avançado ser apresentado como solução para muitos problemas econômicos, a melhoria do padrão de vida da maior parte da população não se tem beneficiado da alta tecnologia produzida. Em vez 
disso, o emprego ainda se tem caracterizado pela proletarização e desespecialização (Burbules \& Torres, 2004), resultado, na maioria dos casos, da crescente desresponsabilização do Estado nas políticas sociais para a saúde, previdência social e educação (Morrow \& Torres, 2004). Essa crise no trabalho afeta de variados modos a educação na sua finalidade básica de atuar na formação do trabalhador. É nessa perspectiva que o discurso presente nas reformas educacionais passa a estar mais vinculado ao mercado de trabalho instável e competitivo, formulando propostas curriculares que produzam sujeitos com novas habilidades e capacidade flexíveis para adaptar-se às novas exigências do mundo do trabalho. Também o conteúdo para a formação do trabalhador sofre alterações, pois se valorizam mais as competências básicas e habilidades, ou seja, o "domínio dos instrumentos para acesso ao conhecimento, do que propriamente a aquisição do repertório dos saberes socialmente construídos" (Dias, 2002, p. 67). Enfatiza-se no discurso curricular a idéia de conhecimento e aprendizagem de caráter instrumental, na qual a finalidade da educação passa a ser a resposta para a seguinte questão: "para que serve isso?".

A cultura da performatividade (Lyotard, 2002) pode ser identificada nos discursos educacionais que defendem "um melhor desempenho estudantil em uma variedade de habilidades" (Lingard, 2004, p. 66). Na busca de eficácia na educação, os desempenhos desejados são estimulados "por meio de um sistema de recompensas e sanções baseado na competição e na performatividade" (Ball, 2004, p. 1.107), no qual estão presentes métodos de mensuração e de controle, discursos da responsabilidade, vinculados às formas econômicas do mundo contemporâneo, criando uma política da aprendizagem (idem). Lopes (2004a) lembra-nos de que a existência de modelos de avaliação focalizados nos resultados vincula-se a processos de controle da educação submetidos aos princípios de mercado. Contudo, a lógica do melhor desempenho da performatividade mostra-se contraditória no campo socioeconômico em que se instaura, pois "ela quer, simultaneamente, menos trabalho no contexto da glo- balização (para baixar os custos da produção) e mais trabalho (para aliviar a carga social da população inativa)" (Lyotard, 2002, p. xvii). Em outras palavras, a lógica do desempenho pela performatividade busca a inclusão do indivíduo no mundo produtivo, ao mesmo tempo em que minimiza e otimiza o tempo e as condições de trabalho.

A política da aprendizagem baseada na performatividade tem como discurso sobre o mundo do trabalho a valorização do trabalhador capaz de aprender rapidamente, de trabalhar em equipe, de ser criativo, auto-regulado e sujeito a relações e vínculos de trabalho mais instáveis. Essa política traduz-se no "aprender a aprender", bastante difundido no Relatório Jacques Delors (Delors, 2001). A "empregabilidade", analisada por Bernstein (1998) como indispensável para o desenvolvimento de uma nova habilidade vital, vincula-se ao "aprender a aprender", ao desenvolvimento de competências flexíveis e transferíveis ajustada às contingências tecnológicas, de organização e do mercado. Com a aprendizagem baseada no "aprender a aprender", processos de educação podem ocupar espaço na vida do sujeito de modo permanente.

Nos documentos oficiais da reforma curricular do ensino médio e nos não-oficiais que difundem a reforma, os discursos sobre o mundo do trabalho expressam-se de modo semelhante ao destacado pela análise dos autores citados. Neles, podemos perceber a importância da educação ante os desafios de um mundo em constante mudança, evidenciando, como já apontado por Abreu e Gomes (2004, p. 2.000), uma convergência de discursos que buscam estabelecer uma articulação entre a educação e o panorama mundial. As Diretrizes e Bases da Educação Nacional (LDBEN, lei n. 9.394/96) coloca o ensino médio como etapa da educação básica, tendo "por finalidades desenvolver o educando, assegurar-lhe a formação comum indispensável para o exercício da cidadania e fornecer-lhe meios para progredir no trabalho e em estudos posteriores" (Brasil, 1996, artigo 22). Além disso, ressalta que, como parte do processo educacional, o ensino médio, "deverá vincular-se ao mundo do trabalho e à prática educacional” (idem, artigo $1^{\circ}, \S 2^{\circ}$ ). 
É interessante verificar de que maneira as duas perspectivas apontadas como finalidades do ensino médio também estão presentes nos discursos de outros contextos, como é o caso da proposta curricular para esse nível de ensino e de textos produzidos pelo setor editorial:

[...] preparação e orientação básica para sua integração ao mundo do trabalho, com as competências que garantam seu aprimoramento profissional e permitam acompanhar as mudanças que caracterizam a produção no nosso tempo; o desenvolvimento das competências para continuar aprendendo, de forma autônoma e crítica, em níveis mais complexos de estudos. (Brasil, 1999, p. 6)

Assim é que, mais do que fornecer informações, o Ensino Médio deve se voltar ao desenvolvimento de competências básicas, tanto para o exercício da cidadania quanto para o desempenho de atividades profissionais, na perspectiva de uma aprendizagem permanente e de uma formação continuada. (Scipione, s.d.)

Já as DCNEM argumentam que o ensino médio é básico porque deve ser entendido como "base para a formação de todos e para todos os tipos de trabalho" (Brasil, 1998, artigo 35). Esse argumento coincide com os discursos sobre a formação de um trabalhador flexível, possuidor de conhecimentos gerais, capaz de adaptar-se às diversas atividades de trabalho.

Os documentos oficiais afirmam também que a preparação para o trabalho depende fortemente da capacidade de aprendizagem. Entretanto, não há discussão de outros aspectos (sociais, econômicos etc.) que podem afetar a capacidade de aprendizagem de cada indivíduo, como também não se questiona a capacidade de exclusão do mercado de trabalho. Ocorre assim uma naturalização dos aspectos excludentes do mundo do trabalho, pela valorização (ou supervalorização) das "novas" qualidades que esse indivíduo deve possuir na sociedade contemporânea. O discurso da aprendizagem permanente, $\mathrm{o}$ "aprender a aprender", é incorporado nos documentos brasileiros, enfatizando a formação continuada "em função dos processos sociais que se modificam" (Brasil, 1999, p. 10), e as alternativas de organização curricular, como as competências, que fornecem bases para a aprendizagem ao longo da vida, de acordo com "o novo significado do trabalho no contexto da globalização econômica" (idem, p. 14).

Os textos oficiais ressaltam ainda que a preparação para o trabalho está interligada aos conhecimentos científico-tecnológicos cada vez mais valorizados, os quais são entendidos como imprescindíveis no mundo do trabalho. A LDBEN aponta como uma das finalidades do ensino médio "a compreensão dos fundamentos científico-tecnológicos dos processos produtivos, relacionando a teoria com a prática, no ensino de cada disciplina" (Brasil, 1996, artigo 35, IV). No contexto atual, não importa o conteúdo ou a informação, consideradas as constantes mutações e os avanços no campo científico-tecnológico, e sim o que está além do conhecimento e da informação: a aplicabilidade do conhecimento (Dias, 2004).

Abreu (2001) afirma que a valorização dos conhecimentos científico-tecnológicos surge da forte associação entre tecnologia e ciência, na qual a aplicabilidade da tecnologia é fundamental para a resolução de problemas na área científica. Ainda segundo a autora, as relações de poder e controle relativos à ciência, à tecnologia e ao mundo do trabalho são responsáveis pelas influências e posicionamentos dos processos de recontextualização dos discursos circulantes na sociedade.

Partindo da perspectiva de que os discursos sobre o mundo do trabalho são apropriados e recontextualizados pelos livros didáticos, analisamos a importância desses materiais para a constituição das políticas curriculares.

\section{O livro didático como constituidor de políticas curriculares}

O livro didático faz parte da construção do currículo e, como tal, deve ser entendido como uma construção sócio-histórica formada por intenções, realidades e decisões provenientes de diferentes indivíduos 
e contextos. Assim, não pode ser considerado elemento inocente e neutro de transmissão desinteressada do conhecimento social (Moreira \& Silva, 1999).

Os livros didáticos são produções culturais, resultados concretos de disputas sociais relacionadas com decisões e ações curriculares. Podemos afirmar, com base nos estudos de Goodson (1998, p. 21), que esses materiais constituem um currículo escrito, o qual nos proporciona um testemunho, uma fonte documental, bem como "um dos melhores roteiros oficiais para a estrutura institucionalizada da escolarização".

Dessa forma, as investigações sobre os livros, a partir de uma perspectiva sócio-histórica, podem levar-nos a compreender a produção desses materiais, o estudo dos elementos implícitos e explícitos que caracterizam, orientam e determinam as finalidades do livro didático, esclarecendo como acontecem a apropriação e a recontextualização dos diversos textos participantes desse processo de construção.

Igualmente, o livro didático não deve ser visto apenas como veículo de reprodução vertical de sentidos e de finalidades das políticas curriculares. Concordamos com Ball (1999) no que se refere à existência de diferentes contextos que funcionam como espaços de negociação e formação das políticas curriculares. Esses espaços simbólicos não possuem fronteiras delimitadas com exatidão, como também seus significados não se limitam ao contexto de origem; eles podem transitar livremente entre os diferentes espaços. Isso acontece porque, por exemplo, os participantes da construção do livro didático também são integrantes de outros contextos, e seus textos produzidos em determinado espaço transitam por outros espaços, adquirindo novos sentidos e interpretações.

Ball (1999) identifica três diferentes contextos que participam da elaboração das políticas curriculares: o contexto da influência, no qual as definições e os discursos políticos são iniciados e/ou construídos; o contexto da produção, no qual textos com as definições políticas selecionadas anteriormente são produzidos; e o contexto da prática, no qual as definições curriculares são recriadas e reinterpretadas. É nesse último contexto que as definições curriculares são colocadas em ação (prática), por isso as ações pedagógicas referentes à escola estão nesse espaço, incluindo-se aí também a elaboração do livro didático.

Entretanto, esse processo de elaboração das políticas curriculares não acontece em um único sentido, do contexto da influência (dos organismos internacionais) para o contexto da prática (escola, livros didáticos), por exemplo. Muitos estudos ressaltam que as políticas curriculares costumam apropriar-se de concepções produzidas em diversos contextos, como é o caso da proposta curricular do ensino médio no Brasil (Abreu \& Gomes, 2004; Lopes, 2003, 2004a, 2004b; Silva \& Lopes, 2004). Os PCNEM não se apropriaram somente dos discursos do campo internacional (contexto de influência), mas também de determinados discursos existentes no campo de ensino de cada área de conhecimento, existindo assim uma circularidade das influências e reinterpretações que dependem do grau de articulação dos grupos envolvidos nesse processo.

Nessa perspectiva, consideramos que o livro didático não é apenas um reprodutor das políticas curriculares, na medida em que o campo editorial se apropria das concepções das propostas oficiais e da prática e as reinterpreta de acordo com as suas próprias concepções e finalidades. Novos significados e interpretações formam-se, influenciando não só o contexto escolar como também os contextos que lhe deram origem. Afirmamos, portanto, que os livros didáticos são produtores de políticas curriculares, seja pela manutenção de suas concepções, seja pela reinterpretação e introdução de novas questões trazidas pelas propostas oficiais.

\section{Discursos sobre o mundo do trabalho nos livros didáticos}

Como já dissemos, neste artigo detemo-nos na análise de livros didáticos de química, biologia, matemática e física, da coleção "De olho no mundo do trabalho". A escolha desses materiais para análise é justificada por sua edição posterior aos primeiros documentos oficiais da reforma do ensino médio (Bra- 
sil, 1996, 1998), além de possuírem referências explícitas à apropriação de princípios preconizados nos textos oficiais. Isso se expressa numa valorização do mundo do trabalho e do "novo ensino médio", tanto nos dizeres de divulgação das capas e contracapas quanto nas cartas de apresentação das obras ao professor e/ou ao estudante.

Apesar de os livros pertencerem à mesma coleção, eles não apresentam uma estrutura de organização uniforme. Podemos interpretar isso pelo fato de que, mesmo pertencendo à mesma editora e coleção, os autores de cada livro interpretam de formas diversas as orientações gerais para a elaboração dos materiais didáticos, uma vez que levam em consideração seus interesses e concepções. Observamos também que essas incorporações se diferenciam entre os grupos disciplinares, os quais são considerados espaços de influência na produção das políticas curriculares, assim como na difusão dos discursos curriculares (Lopes, 2003).

Os livros da coleção analisada, na sua maioria, são organizados por unidades gerais, divididas em capítulos, com apresentação do conteúdo respectivo e exercícios ao final. De um modo geral, os livros didáticos pouco alteram sua estrutura, especialmente no que diz respeito à organização dos conteúdos disciplinares, reforçando a estrutura disciplinar do ensino médio (Abreu \& Gomes, 2004).

O livro de química, segundo os autores, surgiu com a finalidade de "se tornar um acessório para o cumprimento da principal função do professor: despertar a 'fome' nos alunos" (Carvalho \& Souza, 2003, p. 2). Assim, afirmam que a intenção da obra é fornecer condições para o desenvolvimento de uma visão atualizada do nosso mundo, estimulando "a instrumentalização da química, ou seja, as habilidades necessárias para a interpretação e aplicação das questões abordadas" (idem, p. 5). O livro apresenta três grandes unidades, relacionadas com a organização do conhecimento químico científico (química geral, físico-química, química orgânica). Quanto à ordem de abordagem dos conteúdos do conhecimento químico escolar apresentados nos capítulos, não existe nenhuma mudança significa- tiva com relação a outros livros da editora. Existem ainda, ao longo dos capítulos, três tipos de seções inseridas na forma de boxes coloridos, denominados "De olho no contexto" e "A química é notícia", que têm a função de relacionar a química com o contexto mais amplo do dia-a-dia, e "De olho no mundo do trabalho", no qual se propõe uma correspondência entre os conceitos da química e o seu uso em diversas profissões de nível superior ou médio.

Já o livro de biologia apresenta os conteúdos em sete unidades, de acordo com os últimos avanços dessa área, segundo o autor, e abordando temas transversais como ambiente, biotecnologia, saúde e sexualidade (Machado, 2003). Ao longo dos capítulos também existem textos complementares, na forma de boxes coloridos, organizados e denominados pelo autor, no encarte Assessoria Pedagógica, de: a) boxes sobre profissões, "De olho no mundo do trabalho" e "Produção! O mundo do trabalho", que apresentam a conexão entre os conceitos de biologia e sua utilidade no contexto profissional do mundo atual; $b$ ) boxes sobre questões diversificadas, como a associação da biologia com as outras áreas de conhecimento no estudo de um problema, no bloco "Interdisciplinaridade! Associando conhecimentos", as recentes pesquisas científicas para aprofundamento, no "Biodescoberta!", a ligação entre a biologia e aspectos de saúde, no "Sexualidade! Orientação sexual", ou ainda de que maneira utilizar o conteúdo de biologia como gerador de soluções para os problemas do dia-a-dia, no "De olho no contexto"; c) boxes com propostas de atividades, como o "Cidadania: participação social", o "Fórum de discussão" e o "Entrevista! Aprendendo com quem faz", que estimulam a iniciativa e a tomada de decisões, bem como o trabalho em equipe, a integração e o convívio social equilibrado, ou ainda o "Investigação! Experimento simples", no qual uma atividade prática é incentivada; d) e boxes que explicam o significado de termos específicos citados nos capítulos, no "Termos de biologia", ou que indicam referências bibliográficas na internet para aprofundamento dos temas, no "Busca! Fontes de pesquisa". 
Com o livro de matemática, a disciplina aproveita-se da discussão central do mundo do trabalho para mostrar sua importância em todos os campos do conhecimento e sua aplicação em variados contextos profissionais, levando aos alunos

as principais idéias e conceitos da matemática no ensino médio, relacionando-os permanentemente com o mundo do trabalho e com as mais diversas e fascinantes aplicações da matemática no mundo que nos cerca. [...] a matemática será sempre uma poderosa linguagem de estudo e desenvolvimento, seja qual for a área do conhecimento à qual você pretenda se dedicar. (Youssef, Soares \& Fernandez, 2004, p. 3)

Entre os objetivos declarados pelos autores no texto de apresentação do livro está o de fazer o aluno ter resposta para a seguinte pergunta: "para que eu tenho que aprender isso?" (idem, ibidem). Essa questão relaciona-se com os aspectos operacionais e instrumentais do conhecimento, como apontado por Lyotard (2002), característicos da performatividade do ensino. Os autores também vão defender que o modo como o livro foi organizado pretende garantir ao aluno a percepção das aplicações para utilizar-se do conhecimento matemático nos mais variados contextos de resolução de problemas em sua futura profissão (idem, ibidem). Desse modo, a cada capítulo o livro faz "chamadas" para a introdução de conceitos de idéias matemáticas, relacionando-os à utilização em determinadas profissões. Apresenta ainda quatro seções destacadas, sendo uma delas o boxe sobre profissões, "De olho no mundo do trabalho", e outras três intituladas "De olho na história da matemática", mostrando a evolução da construção e o desenvolvimento dos conceitos matemáticos na história da humanidade, "De olho no contexto", com aplicações da matemática no dia-a-dia, e "De olho na...", associando a matemática a disciplinas como física, arte etc.

No livro de física, os discursos sobre o mundo do trabalho são desenvolvidos em seu capítulo inicial, cuja temática é "a Física no campo da ciência". Nesse capítulo introdutório são apresentadas as relações da física com os avanços científico-tecnológicos no mundo contemporâneo. Entre os objetivos do ensino de física, apontados pelos autores, está o de que o aluno possa, ao longo do curso, responder às seguintes questões: "por que preciso adquirir esses conhecimentos?" e "para que eles irão me servir?" (Máximo \& Alvarenga, 2003, p. 11). Essas questões são defendidas pelos autores como importantes para que os alunos compreendam o papel da ciência e das suas técnicas. Novamente, podemos perceber nessas questões a idéia de aplicabilidade do conhecimento, acentuando seu caráter instrumental. Há, ao longo do livro, a apresentação de uma seção intitulada "História e contextos", com o objetivo de destacar a história da física e a aplicação dos conceitos da disciplina em contextos variados, além da seção "De olho no mundo do trabalho".

Com relação aos princípios preconizados pelos documentos oficiais da reforma, chama-nos a atenção a valorização do discurso do mundo produtivo pelo próprio título da coleção analisada. Segundo Machado, "o pensar de modo criativo, crítico e autônomo é uma condição essencial para o sucesso no mundo do trabalho" (Machado, 2003, p. 3). O autor ainda trata da formação para o trabalho em um mundo em mutação, dizendo que o objetivo da obra é favorecer os alunos na "busca permanente de novas e importantes competências que os acompanharão pela vida afora", tornando-os aptos "a fazer uso de novas tecnologias, vencendo os desafios que a vida impõe" (idem, ibidem).

Nos dizeres das capas, contracapas e na apresentação, existe uma preocupação com um indivíduo criativo, autônomo, crítico, cooperativo, que deve ser formado pela escola. Pede-se prioridade para conhecimentos e competências mais gerais, uma vez que estes serão essenciais "para a inserção do aluno no mercado de trabalho e para a continuidade dos seus estudos" (idem, p. 4). A preocupação com a formação contínua do indivíduo vai ao encontro das orientações dos discursos sobre o mundo do trabalho relacionados à lógica da performatividade. $\mathrm{O}$ trabalhador da sociedade contemporânea deve estar preparado para acompanhar as mudanças dos diferentes contextos, 
sendo flexível, criativo e rápido o bastante para tomar decisões conscientes, além de ter capacidade para aprender continuamente a partir da resolução de problemas.

Com relação aos boxes intitulados "De olho no mundo do trabalho", ${ }^{1}$ comum a todos os volumes analisados dessa coleção, verificamos que são diversas as profissões citadas a fim de estabelecer ligações entre os conteúdos disciplinares e sua aplicação no mundo produtivo, com predominância de profissões de nível universitário.

Das formações de nível universitário, a maioria faz parte do grupo denominado por Bernstein (1996, 1998) como regiões. Nas regiões, a formação está vinculada à aplicação do conhecimento derivado de diversos campos, como é o caso da engenharia, jornalismo, arquitetura, entre outras. As regiões são sintetizadas por Bernstein (1996) como "interface entre as disciplinas e as tecnologias que elas tornam possível” (p. 219). Nos boxes, a maior parte das profissões faz uso de tecnologias avançadas. No livro de física, por exemplo, o físico médico (desenvolve instrumentos e técnicas para o diagnóstico e tratamento de doenças), e no livro de matemática, o cientista da computação (desenvolve ferramentas para o uso do computador).

Quanto às profissões citadas repetidamente (geólogo, veterinário etc.), verificamos que o texto de apresentação não é o mesmo nas diferentes disciplinas. Os textos das referidas profissões possuem encaminhamentos de acordo com o conhecimento disciplinar no qual estão inseridos. Passam, assim, por reinterpretações e recontextualizações segundo a lógica do conhecimento de cada área disciplinar, bem como consideram as finalidades e interesses do grupo disciplinar que participa da elaboração do material didático.

Grande parte das profissões pertence ao setor de produção e serviços, sendo indicados como espaços

${ }^{1}$ A editoração e a redação desses boxes foram realizadas por profissionais integrantes da equipe do Guia do Estudante, da editora Abril. de trabalho os laboratórios de pesquisa em indústrias, bancos de investimento, museus públicos e privados, empresas que empregam tecnologia, grandes obras da construção civil como hidrelétricas, entre outros, acentuando a caracterização do mercado de trabalho como amplo e diversificado. Conceitos e idéias como: eficácia, eficiência, viabilidade econômica, automação, produtividade do sistema, competição no mercado de trabalho e a idéia de versatilidade do profissional, apresentado como "curinga" (Youssef, Soares \& Fernandez, 2004, p. 23), presentes nos discursos sobre o mundo do trabalho na reforma curricular, são incorporados nos textos sobre as profissões. Entendemos que o propósito desses boxes seja também enfatizar conceitos/idéias que fazem parte do discurso sobre o mundo do trabalho presentes nas políticas curriculares do ensino médio.

Ressaltamos que o discurso sobre o mundo do trabalho presente nos livros didáticos se restringe à apresentação das obras e aos boxes que falam sobre as profissões. Em outras palavras, além do texto de apresentação e dos boxes específicos, não existe uma articulação maior entre os conteúdos de cada disciplina e os discursos circulantes sobre o mundo do trabalho. O direcionamento proposto pela coleção analisada concentra-se em um caráter de aplicabilidade do conhecimento e numa conseqüente valorização do conhecimento científico-tecnológico.

\section{Considerações finais}

O discurso do mundo do trabalho cada vez mais ganha destaque no campo educacional, uma vez que outros contextos, como o da produção e da prática, se apropriam e recontextualizam suas orientações.

No caso dos livros didáticos, ocorre a apropriação dos conceitos dos discursos sociais e econômicos que valorizam o conhecimento científico-tecnológico submetido à lógica do mercado, dos conceitos introduzidos por documentos educacionais oficiais e não-oficiais, bem como dos discursos dos próprios autores e dos interesses editoriais. Sendo assim, podemos afirmar que a elaboração do livro didático so- 
fre a influência de todos os contextos que participam do processo de formação das políticas curriculares, ou seja, do contexto de influência até o contexto da prática.

Verificamos que a recontextualização da base proposta para a organização da coleção analisada, o mundo do trabalho, não produziu os mesmos significados nas diferentes disciplinas. Os livros de matemática e de biologia apresentam uma incorporação maior das concepções do novo trabalhador aplicadas à educação, na qual o desenvolvimento de competências e habilidades desejáveis para o futuro trabalhador deve capacitá-lo ao ajuste das variadas situações de trabalho. Já nos livros de química e física, a preocupação maior é a utilidade do conhecimento disciplinar no contexto social mais amplo, relacionado principalmente ao setor produtivo e às tecnologias.

A ressignificação sobre o discurso do mundo do trabalho pelas disciplinas analisadas acarreta diferentes sentidos para a aplicabilidade do conhecimento. Diferenças essas que levam em consideração os interesses e as finalidades de cada grupo disciplinar durante o processo da recontextualização. Na química e na física, a aplicabilidade do conhecimento concentra-se na contextualização das tecnologias relacionadas ao cotidiano e ao mundo produtivo, como forma de valorizar o conhecimento científico-tecnológico específico de cada área. Já a biologia e a matemática apresentam um discurso que valoriza a aplicabilidade do conhecimento pelas competências e habilidades ligadas à idéia da performatividade do trabalho, além das questões citadas nas outras disciplinas.

Entretanto, existe um traço de similaridade entre os livros, na medida em que todas as disciplinas incorporam o princípio de aplicabilidade do conhecimento na apresentação das profisssões. Todas as disciplinas utilizam as profissões como meio de aplicar o conhecimento de determinado conteúdo curricular especializado, fazendo com que elas funcionem mais como uma ferramenta para demonstrar a utilidade do conhecimento científico, como uma tecnologia que tem o objetivo principal de ressaltar e valorizar os conhecimentos específicos da área.
Outro ponto a considerar é que essa aplicabilidade do conhecimento não produz alterações significativas na seleção e organização dos conteúdos disciplinares da coleção, não contribuindo assim para o questionamento da construção do currículo, nem dos conhecimentos considerados socialmente válidos. Em outras palavras, a utilização do discurso do mundo do trabalho pela lógica da performatividade implica a manutenção da disciplina como padrão de estabilidade curricular (Goodson, 1997) para a coleção analisada.

Portanto, além de os livros didáticos dessa coleção terem sofrido a influência de vários contextos durante a sua elaboração, eles também se apresentam como produtores de diversos sentidos e posições, como, por exemplo, a valorização da aplicabilidade do conhecimento, a importância do desenvolvimento de competências, a valorização do conhecimento científico-tecnológico e de um maior tempo de escolarização. Essas ressignificações influenciarão a produção das políticas curriculares tanto no contexto da prática quanto no contexto de produção de políticas. Nesse sentido, os livros didáticos assumem um caráter central na discussão e produção de políticas curriculares.

Ressaltamos ainda que não estamos desconsiderando as outras interpretações que os livros didáticos sofrem em outros contextos, como a sala de aula. É bem provável que essas reinterpretações não estejam em consonância com as apresentadas neste artigo, uma vez que levam em consideração outros aspectos por nós não abordados. Entretanto, essas outras reinterpretações não diminuem a importância da nossa análise, seja na investigação dos sentidos e significados que esses materiais trazem, seja na investigação da produção de políticas curriculares, uma vez que a releitura e a reinterpretação desses textos não são totalmente abertas. Destacamos que as políticas curriculares oficiais possuem mecanismos de controle para essa releitura, promovendo, por exemplo, a paráfrase dos textos curriculares por intermédio do mercado editorial. Dessa forma, os livros didáticos tornam-se redutores do caráter polissêmico dos textos curriculares, na medida em que veiculam as leituras 
ditas mais apropriadas para determinado contexto sócio-histórico. Por essa razão, salientamos que o estudo sobre os livros didáticos é de fundamental importância, na medida em que esses textos influenciam mais os contextos escolares do que os próprios textos oficiais.

\section{Referências bibliográficas}

ABREU, Rozana Gomes de. Tecnologia e ensino de ciências: recontextualização no "novo ensino médio". In: ENCONTRO NACIONAL DE PESQUISA E EDUCAÇÃO EM CIÊNCIAS, 3., 2001, Atibaia. Anais... Atibaia: ABRAPEC, 2001. 1 CD-ROM.

GOMES, Maria Margarida. Investigando a contextualização e as tecnologias em livros didáticos de biologia e química para o ensino médio. In: COLÓQUIO SOBRE QUESTÕES CURRICULARES, 6., COLÓQUIO LUSO-BRASILEIRO, 2., 2004, Rio de Janeiro. Anais... Rio de Janeiro: UERJ, 2004. 1 CDROM. p. 2.000-2.015.

BALL, Stephen J. Cidadania global, consumo e política educacional. In: SILVA, Luiz Heron da (Org.). A escola cidadã no contexto da globalização. Petrópolis: Vozes, 1998. p. 121-137.

Education reform - a critical and post-structural approach. Buckingham: Open University, 1999.

Performatividade, privatização e o pós-estado do bem-estar. Educação \& Sociedade, Campinas, v. 25, n. 89, p. 1.1051.126, set./dez. 2004.

BERNSTEIN, Basil. A estruturação do discurso pedagógico. Petrópolis: Vozes, 1996.

. Pedagogía, control simbólico e identidad. Madrid:

Morata, 1998.

BRASIL. Lei n. 9.394, de 20 de dezembro de 1996. Estabelece as diretrizes e bases da educação nacional. Disponível em: <http:// www.presidencia.gov.br/CCIVIL/LEIS/L9394.htm>. Acesso em: 10 mar. 2005.

BRASIL. Ministério da Educação. Diretrizes curriculares nacionais para o ensino médio. In: . Reforma do ensino médio. Brasília: MEC/Secretaria de Educação Média e Tecnológica, 1998. $1 \mathrm{CD}-\mathrm{ROM}$

Parâmetros curriculares nacionais para o ensino médio. In: Reforma do ensino médio. Brasília: MEC/Secretaria de Educação Média e Tecnológica, 1999. 1 CD-ROM. BURBULES, Nicholas; TORRES, Carlos Alberto. Globalização e educação: uma introdução. In: BURBULES, Nicholas; TORRES, Carlos Alberto (Orgs.). Globalização e educação. Porto Alegre: Artes Médicas, 2004. p. 11-26.

CARVALHO, Geraldo Camargo de; SOUZA, Celso Lopes de. Química (Assessoria Pedagógica encartada). São Paulo: Scipione, 2003 (Coleção De Olho no Mundo do Trabalho).

DELORS, Jacques (Org.). Educação: um tesouro a descobrir. Relatório para a UNESCO da Comissão Internacional sobre a Educação para o Século XXI. São Paulo: Cortez; Brasília: MEC/ UNESCO, 2001.

DIAS, Rosanne Evangelista. Competências: um conceito recontextualizado no currículo para a formação de professores no Brasil. 2002. 160f. Dissertação (Mestrado) - Faculdade de Educação, Universidade Federal do Rio de Janeiro, Rio de Janeiro, 2002.

Discurso das competências no manual do professor - um estudo sobre os livros didáticos do ensino médio. In: COLÓQUIO SOBRE QUESTÕES CURRICULARES, 6., COLÓQUIO LUSO-BRASILEIRO, 2., 2004, Rio de Janeiro. Anais... Rio de Janeiro: UERJ, 2004. 1 CD-ROM. p. 4.485-4.500.

GOODSON, Ivor. A construção social do currículo. Lisboa: Educa, 1997.

Currículo: teoria e história. Petrópolis: Vozes, 1998.

LINGARD, Bob. É ou não é: globalização vernacular, política e reestruturação educacional. In: BURBULES, Nicholas; TORRES, Carlos Alberto (Orgs.). Globalização e educação. Porto Alegre: Artes Médicas, 2004. p. 59-76.

LOPES, Alice Casimiro. Hibridismo de discursos curriculares na disciplina escolar química. In: REUNIÃO ANUAL DA SOCIEDADE BRASILEIRA DE QUÍMICA, 26., 2003, Poços de Caldas. Anais... Poços de Caldas: Sociedade Brasileira de Química, 2003. Disponível em:<www.sbq.org.br>. Acesso em: 12 dez. 2003. . Interpretando e produzindo políticas curriculares para o ensino médio. In: FRIGOTTO, Gaudêncio; CIAVATTA, Maria (Orgs.). Ensino médio: ciência, cultura e trabalho. Brasília: MEC, 2004a.

Políticas de currículo: continuidade ou mudança de rumos? Revista Brasileira de Educação, Rio de Janeiro/Campinas: ANPEd/Autores Associados, n. 26, p. 109-118, maio/jun./jul./ ago. 2004b.

LYOTARD, Jean-François. A condição pós-moderna. Tradução Ricardo Corrêa Barbosa. 7. ed. Rio de Janeiro: José Olympio, 2002. MACHADO, Sídio. Biologia (Assessoria Pedagógica encartada). 
São Paulo: Scipione, 2003 (Coleção De Olho no Mundo do Trabalho, v. único).

MÁXIMO, Antônio; ALVARENGA, Beatriz. Física (Assessoria Pedagógica encartada). São Paulo: Scipione, 2003 (Coleção De Olho no Mundo do Trabalho, v. único).

MELLO, Josefina Carmen Diaz de. O livro didático como currículo escrito. In: COLÓQUIO SOBRE QUESTÕES CURRICULARES, 6., COLÓQUIO LUSO-BRASILEIRO, 2., 2004, Rio de Janeiro. Anais... Rio de Janeiro: UERJ, 2004. 1 CD-ROM. p. 2.6812.697.

MOREIRA, Antônio Flávio Barbosa; SILVA, Tomaz Tadeu da. Sociologia e teoria crítica do currículo: uma introdução. In: MOREIRA, Antônio Flávio; SILVA, Tomaz Tadeu (Orgs.). Currículo, cultura e sociedade. 3. ed. São Paulo: Cortez, 1999.

MORROW, Raymond Allen; TORRES, Carlos Alberto. Estado, globalização e políticas educacionais. In: BURBULES, Nicholas; TORRES, Carlos Alberto (Orgs.). Globalização e educação. Porto Alegre: Artes Médicas, 2004. p. 27-44.

SCIPIONE. Scipione Educação. Artigos. PCN ensino médio: aspectos resumidos e comentados. [s.d.]. Disponível em: $<$ http:// www.scipione.com.br/educa/artigos/artigos.asp/pcn_ensino médio $>$. Acesso em: 25 fev. 2004.

SILVA, Denys Brasil; LOPES, Alice Casimiro. Livros didáticos de física na produção de políticas curriculares. In: COLÓQUIO SOBRE QUESTÕES CURRICULARES, 6., COLÓQUIO LUSOBRASILEIRO, 2., 2004, Rio de Janeiro. Anais... Rio de Janeiro: UERJ, 2004. 1 CD-ROM. p. 2084-2098.

YOUSSEF, Antonio Nicolau; SOARES, Elizabeth; FERNANDEZ, Vicente Paz. Matemática (Assessoria Pedagógica encartada). São Paulo: Scipione, 2004 (Coleção De Olho no Mundo do Trabalho, v. único).

ROSANNE EVANGELISTA DIAS, mestre em educação pela Universidade Federal do Rio de Janeiro (UFRJ) e doutoranda em educação pela Universidade do Estado do Rio de Janeiro (UERJ), professora do Setor Curricular Multidisciplinar do Colégio de Aplicação da UFRJ. Publicou recentemente: Competências na formação de professores no Brasil: o que (não) há de novo, em co-autoria com Alice Casimiro Lopes (Educação \& Sociedade, Campinas, v. 24, n. 85, p. 1.155-1.177, dez. 2003); Discurso das competências nos manuais do professor - um estudo sobre os livros didáticos do Ensino Médio (In: $2^{\circ}$ Colóquio Luso-Brasileiro sobre questões curriculares. Rio de Janeiro: UERJ, ago. 2004. 1 CD-ROM); Conhecimento e interesse na produção de políticas curriculares, em co-autoria com Silvia Braña López (In: $3^{\circ}$ Colóquio Luso-Brasileiro sobre questões curriculares. Braga: Universidade do Minho, fev. 2006). Integra o grupo de pesquisa do Conselho Nacional de Desenvolvimento Científico e Tecnológico (CNPq) “Currículo: sujeitos, conhecimento e cultura", participando da pesquisa "A produção de políticas de currículo em contextos disciplinares", coordenada pela professora Alice Casimiro Lopes. E-mail: rosanne@ufrj.br

ROZANA GOMES DE ABREU, mestre em educação pela Universidade Federal do Rio de Janeiro (UFRJ) e doutoranda em educação pela Universidade do Estado do Rio de Janeiro (UERJ), é professora do Setor Curricular de Química do Colégio de Aplicação da UFRJ. Publicou recentemente: Tecnologia e ensino de ciências: recontextualização no "Novo Ensino Médio" (In: $3^{\circ}$ Encontro Nacional de Pesquisa e Educação em Ciências. Atibaia: ABRAPEC, 2001. 1 CD-ROM); Investigando a contextualização e as tecnologias em livros didáticos de biologia e química para o ensino médio, em co-autoria com Maria Margarida Gomes (In: $2^{\circ}$ Colóquio Luso-Brasileiro sobre questões curriculares. Rio de Janeiro: UERJ, ago. 2004. 1 CD-ROM); Concepções curriculares do grupo disciplinar de química e produção de políticas para o ensino médio (In: $3^{\circ}$ Colóquio Luso-Brasileiro sobre questões curriculares. Braga: Universidade do Minho, fev. 2006). Integra o grupo de pesquisa do Conselho Nacional de Desenvolvimento Científico e Tecnológico (CNPq) "Currículo: sujeitos, conhecimento e cultura", participando da pesquisa "A produção de políticas de currículo em contextos disciplinares", coordenada pela professora Alice Casimiro Lopes. E-mail: rozana@cap.ufrj.br

Recebido em novembro de 2005 Aprovado em março de 2006 
context of the reconstruction of the public sphere in Latin America. It is argued, after returning to the social and pedagogical locations where popular education originated, that a distinctive trait of popular education is the notion of search itself, in the same sense that the Latin American identity itself constitutes a similar space of possibilities. This is followed by an analysis of some clandestine pedagogical strategies, thus understood since they are characterized respectively as absence or for what is hidden by hegemonic pedagogical theory: pedagogy of survival, of resistance, and of relation. At the end there is an allusion to the image of the labyrinth for defining the perplexities - past and present - of popular education.

Key-words: popular education; Latin America; public sphere; clandestine pedagogies

\section{La educación popular y la} reconstrucción del público. ¿Hay fuego sobre las brasas?

El artículo busca ubicar la educación popular en el contexto de la reconstrucción de la esfera pública en América Latina. A partir de la vuelta a sus orígenes para identificar el lugar social y los espacios pedagógicos en los cuales la misma se originó, argumenta que un trazo distintivo de la educación popular es la propia búsqueda, en el mismo sentido en que la identidad latinoamericana se constituye como este lugar de posibilidades. A seguir analiza algunas estrategias pedagógicas clandestinas, así entendidas por caracterizarse como ausencia u ocultación, respectivamente: pedagogía de la sobrevivencia, de la resistencia y de la relación. Al final, retorna a la imagen del laberinto para definir las perplexidades - históricas y actuales - de la educación popular.
Palabras claves: educación popular; América Latina; esfera pública; pedagogías clandestinas

Elizabeth Macedo

\section{Currículo como espaço-tempo de fronteira cultural}

A autora defende que o currículo precisa ser pensado como espaço-tempo de fronteira entre culturas, garantindo a centralidade da categoria cultura em detrimento do conhecimento, caro à pedagogia crítica e ainda hoje embasando as discussões do campo. Utiliza-se, na construção da argumentação, de discussões pós-coloniais, especialmente as contribuições de $\mathrm{H}$. Bhabha, S. Hall e B. S. Santos. Conclui que tratar o currículo como entre-lugar cultural em que se expressam princípios do Iluminismo e do mercado, mas também alternativas geradas na ambivalência dos globalismos, pode permitir ao currículo rearticular sua dimensão política na contemporaneidade. Palavras-chave: currículo; póscolonialismo; cultura

\section{Curriculum as the space-time of cultural frontier}

The author defends the position that the curriculum should be thought of as the space-time frontier between cultures. In so doing, the text proposes to guarantee the centrality of the category culture over knowledge, which is important to critical pedagogy and fundamental to the discussions within this field. Post-colonial theories as proposed by H. Bhabha, S. Hall and B. S. Santos are the theoretical contributions that sustain the argumentation. The text argues that to think about curriculum as a cultural in-between where we can find contributions from Illuminist theory and the market, as well as alternatives created in the ambivalence of these global discourses, can rearticulate the political dimension of curriculum in contemporary society.

Key-words: curriculum; post-

colonialism; culture

\section{Currículo como espacio-tiempo de frontera cultural}

La autora defiende que el currículo precisa ser pensado como espaciotiempo de frontera entre culturas, garantiendo la centralidad de la categoría cultural en detrimento del conocimiento, caro a la pedagogía crítica y todavía hoy sirve de base a las discusiones del campo. Se utiliza en la construcción de la argumentación, de discusiones pos-coloniales, especialmente las contribuciones de $H$. Bhabha, S. Hall y B. S. Santos. Concluye que tratar el currículo como entre-lugar cultural en que se expresan principios del iluminismo y del mercado, mas también alternativas generadas en la ambivalencia de los globalismos, puede permitir al currículo rearticular su dimensión politica en la contemporanidad.

Palabras claves: currículo; poscolonialismo; cultura

Rosanne Evangelista Dias e Rozana Gomes de Abreu

Discursos do mundo do trabalho nos livros didáticos do ensino médio

Neste estudo, focalizamos os discursos sobre o mundo do trabalho nos livros didáticos da área de ciências da coleção De olho no mundo do trabalho (editora Scipione), como parte de uma política curricular para o ensino médio. Entendemos a constituição de políticas curriculares como um processo de negociação complexo que inclui influência, produção e disseminação de textos circulantes que estão sujeitos à recriação contínua no contexto da prática (Ball). Analisamos como os discursos sobre o mundo do trabalho são apropriados e recontextualizados (Bernstein) na elaboração de livros di- 
dáticos e quais novos sentidos e significados são produzidos. Identificamos no discurso sobre a formação para o trabalho sentidos e significados que precisam ser refletidos pela comunidade educacional, considerando as relações estabelecidas entre os contextos econômico e educacional que resultam em formas de ensino e aprendizagem que acentuam o caráter de performatividade (Lyotard).

Palavras-chave: ensino médio; livro didático; políticas curriculares; trabalho

Discourse on the world of work in secondary school textbooks

In this study, we focus on discourse on the world of work in science textbooks of the collection With an eye on the world of work (De olho no mundo do trabalho), published by Scipione, as part of a curriculum policy for secondary education. We understand that the construction of curriculum policies is a complex process of negotiation that includes influence, production and dissemination of texts which circulate and which are subject to continuous recreation in the context of practice. We analyse how discourse on the world of work is appropriated and re-contextualised in the elaboration of school textbooks and what new meanings are produced. In the discourse on training for work, we identify meanings that the educational community needs to reflect upon, considering the relations established between educational and economic contexts that result in forms of teaching and learning, accentuating the character of performance.

Key-words: secondary education; textbook; curriculum policies; work and education

Discursos del mundo del trabajo en los libros didácticos de la enseñanza secundaria

En este estudio, enfocamos los discursos sobre el mundo del trabajo en los libros didácticos de la área de ciencias de la colección De ojo en el mundo del trabajo (editora Scipione), como parte de una política curricular para la enseñanza secundaria. Entendemos la constitución de políticas curriculares como un proceso de negociación complejo que incluye influencia, producción y diseminación de textos circulantes, que están sujetos a la recreación continua en el contexto de la práctica (Ball). Analisamos como los discursos sobre el mundo del trabajo son apropiados y contextualizados (Bernstein) en la elaboración de libros didácticos y en los cuales los nuevos sentidos y significados son producidos. Identificamos en el discurso sobre la formación para el trabajo, sentidos y significados, que precisan ser pensados por la comunidad educacional, considerando las relaciones establecidas entre los contextos económico y educacional que resultan en formas de enseñanza y aprendizaje que acentuan el caracter de performatividad (Lyotard).

Palabras claves: enseñanza secundaria; libro didáctico; políticas curriculares; trabajo

Isabel Cristina de Moura Carvalho

As transformações na esfera pública e a ação ecológica: educação e política em tempos de crise da modernidade

Discute as transformações da esfera pública contemporânea e a emergência de novos modos de ação política associados à formação de um campo político e pedagógico ambiental. Afirma que a ação política ambiental, no contexto do ambientalismo e da nova esquerda contracultural, pode ser considerada uma das expressões da crise da modernidade. Nesse sentido, os movimentos ecológicos buscam reposicionar o ego e o socius, o privado e o público, a ética e a estética na esfera de ação societal. Isso repõe um dilema que remete tanto às tendências conflitivas da modernidade quanto ao seu projeto emancipatório. Ante essa problemática, algumas análises destacam a dissolução e o declínio da política, enquanto outras enfatizam a emergência de uma nova forma de ação política. Por fim, o artigo explora os rebatimentos dessas mudanças sociais no campo da ação educativa, particularmente a educação ambiental, preocupada com a construção de um sujeito ecológico.

Palavras-chave: ação política; modernidade; educação ambiental; sujeito ecológico

Changes in the public sphere and ecological action: education and politics in the crisis of modernity The article discusses transformations in the contemporary public sphere and the emergence of new types of political action, which are related to the creation of a political and pedagogical environmental field. The political environmental action may be considered as part of the counterculture and the new left movements. Therefore, it may be taken as one of the expressions of the crisis of modernity, which is redefining the role of social action in terms of individual, private, public, ethical and aesthetic action. This dilemma exposes the conflicts which constitute modernity and its emancipating project. In the face of this problematic, some analyses emphasise the dissolution and the decline of politics whilst others underline the emergence of a new way of doing politics. Finally, the article explores the aftermaths of these social changes in the educational field, especially in environmental education, which is concerned with the construction of an ecological self. Key-words: political action; modernity; environmental education; ecological self 